\title{
PENINGKATAN KETERBUKAAN DIRI (Self-Disclosure) DENGAN TEKNIK PETAK JOHARI MELALUI BIMBINGAN KELOMPOK DI SMA NEGERI 2 DI KOTA BENGKULU KELAS X MIPA F
}

\author{
Anik Febriyanti \\ Guru BK SMA TENERA PT AGRICINAL BENGKULU UTARA \\ e-mail: anikfebriyanti@gmail.com
}

\begin{abstract}
Openness Self(Self-Disclosure) is the attitude of the individual able and willing to provide information about himself personally, and open and willing to accept the opinions of others to trust someone to be a friend to share. This study aims to: 1) Knowing how the level of the Self Disclosure students at SMAN 2 Bengkulu city F Class $\mathrm{X}$ Mathematics and Natural Sciences before being awarded with Technical Guidance Services Group Plots Johari. 2) Knowing how the level of the Self Disclosure students at SMAN 2 Bengkulu city F Class X Mathematics and Natural Sciences after being awarded with Technical Guidance Services Group Plots Johari. 3) Knowing the success of the group with technical guidance services Johari plots in increasing Disclosure Selfstudent at SMAN 2 Bengkulu city F Class X Mathematics and Natural Sciences. The method used in the research was a class act. The subjects were students of class XI SMA N 2 F MIPA Bengkulu City. The procedure of classroom action research conducted through four (4) stages: 1) planning, 2) implementation, 3) observation, 4) Reflection. Once the data is collected and analyzed obtained the following results: (1) At each cycle of increased openness Yourself students, On Pre Test of 30 students there are eight students who have low levels of self openness as much as 5 students with a percentage of $62.5 \%$ and the level of openness Being self as much as 3 students with a percentage of $37.5 \%$. (2) In the first cycle, the level of openness of students improve their self becomes Self Disclosure levels were as much as 6 students with a percentage of $75 \%$ and a high level of self Disclosure much as 2 people with a percentage of $25 \%$. In the third cycle, the degree of openness of the Self increases to moderate as much as 1 students with a percentage of $12.5 \%$ and higher by 7 students with a percentage of $87.5 \%$. (3) Implementation Guidance Services group with Johari plot technique can increase the level of self Disclosure students at SMAN 2 Bengkulu city F Class X Mathematics and Natural Sciences Academic Year
\end{abstract}

Keywords: openness Self(Self-Disclosure); Window Johari; Group conseling

\begin{abstract}
ABSTRAK
Keterbukaan Diri (Self-Disclosure) adalah sikap individu yang mampu dan mau memberikan informasi dirinya secara pribadi dan terbuka serta mau menerima pendapat orang lain dengan mempercayai seseorang untuk dijadikan teman berbagi. Penelitian ini bertujuan untuk : 1) Mengetahui bagaimana tingkat Keterbukaan Diri siswa di SMA Negeri 2 Kota Bengkulu Kelas X Mipa F sebelum diberikan Layanan Bimbingan Kelompok dengan Teknik Petak Johari. 2) Mengetahui bagaimana tingkat Keterbukaan Diri siswa di SMA Negeri 2 Kota Bengkulu Kelas X Mipa F setelah diberikan Layanan Bimbingan Kelompok dengan Teknik Petak Johari. 3) Mengetahui keberhasilan layanan Bimbingan kelompok dengan teknik Petak Johari dalam meningkatkan Keterbukaan Diri siswa di SMA Negeri 2 Kota Bengkulu Kelas X Mipa F. Metode yang digunakan dalam penelitian adalah penelitian tindakan kelas. Subjek penelitian adalah siswa kelas XI MIPA F SMA N 2 Kota Bengkulu. Prosedur penelitian tindakan kelas dilaksanakan melalui 4 (empat) tahap yaitu 1) perencanaan, 2) pelaksanaan, 3)Observasi, 4)Refleksi. Setelah data terkumpul dan dianalisis diperoleh hasil penelitian sebagai berikut: (1) Pada setiap siklus terjadi peningkatan Keterbukaan Diri siswa, Pada Pre Test dari 30 siswa terdapat 8 siswa yang memiliki tingkat Keterbukaan Diri rendah sebanyak 5 siswa dengan presentase 62,5\% dan tingkat Keterbukaan Diri Sedang sebanyak 3 siswa dengan presentase 37,5 \%. (2) Pada siklus I, tingkat Keterbukaan Diri siswa meningkatkan menjadi tingkat Keterbukaan Diri sedang sebanyak 6 siswa dengan presentase $75 \%$ dan tingkat Keterbukaan Diri tinggi sebanyak 2 orang dengan presentase $25 \%$. Pada siklus III, tingkat Keterbukaan Diri meningkat menjadi sedang sebanyak 1 siswa dengan presentase $12,5 \%$ dan tinggi sebanyak 7 siswa dengan presentase 87,5 \%. (3)Pelaksanaan Layanan Bimbingan kelompok dengan Teknik Petak Johari dapat meningkatkan tingkat Keterbukaan Diri siswa di SMA Negeri 2 Kota Bengkulu Kelas X Mipa F.
\end{abstract}

\section{Kata Kunci: keterbukaan Diri (Self-Disclosure); Petak Johari ; Bimbingan kelompok}




\section{Pendahuluan}

Salah satu indikasi bahwa manusia sebagai makhluk sosial adalah perilaku komunikasi antar manusia. Manusia tidak dapat hidup sendiri, pasti membutuhkan orang lain. Dari lahir sampai mati, cenderung memerlukan bantuan dari orang lain. Kecenderungan ini dapat dilihat dalam kehidupan sehari-hari yang menunjukkan fakta bahwa semua kegiatan yang dilakukan manusia selalu berhubungan dengan orang lain. Setiap orang akan melakukan suatu komunikasi agar dapat berhubungan dengan sesama seperti yang dijelaskan Deddy Mulyana 2008 (dalam Suranto. 2011: 3) bahwa komunikasi interpersonal atau komunikasi antar individu merupakan komunikasi antar orang-orang secara tatap muka, yang memungkinkan setiap pesertanya menangkap reaksi orang lain secara langsung baik verbal maupun nonverbal.

Sebagaimana orang berinteraksi dalam hubungan, mereka akan terlibat pada tingkat tertentu pada pengungkapan terhadap satu sama lain dan mereka akan memberikan sejumlah umpan balik, hubungan antarpribadi yang sehat ditandai oleh keseimbangan keterbukaan diri (SelfDisclosure) yang tepat yaitu saling memberikan data biografis, gagasangagasan pribadi, dan perasaan-perasaan yang tidak diketahui bagi orang lain, dan umpan balik berupa verbal dan respon- respon fisik kepada orang dan/atau pesanpesan mereka di dalam suatu hubungan.

Berdasarkan hasil pengamatan peneliti terhadap hubungan antarpribadi dan Keterbukaan Diri (Self-Disclosure) siswa dengan teman sebayanya di SMA N 2 Kota Bengkulu kurang efektif, mereka cenderung menutup diri dengan alasan belum percaya dan masih membentuk kelompok, mereka kurang percaya diri dalam bergaul dan cenderung membatasi diri dengan hanya berteman dengan beberapa orang, seperti berteman dengan teman saat masih duduk di bangku SMP, dengan begitu tentu akan terjadi kesenjangan dalam hubungan antarpribadi serta siswa menjadi tertutup dan tidak mampu membuka dirinya.

Dengan permasalahan yang terjadi dengan siswa tersebut guru pembimbing telah melakukan tindakan agar permasalahan siswa terentaskan dengan memberikan layanan klasikal yang dilakukan 1x45 menit saat jam sekolah usai, dengan memberikan berbagai materi yang berhubungan dengan komunikasi antar pribadi atau materi tentang membuka diri, namun setelah diberikan perlakuan, guru pembimbing merasa bahwa cara tersebut belum efektif. Hal ini dibuktikan dengan masih banyaknya siswa yang masih menutup diri, kurang percaya diri, belum memiliki teman dekat dan keluhan dari wali kelas bahwa masih ada siswa 
yang masih menutup dirinya terhadap lingkungan baru seperti berhubungan dengan teman kelasnya serta belum adanya ketertarikan untuk memiliki teman dekat.

Berdasarkan permasalahan di atas peneliti menggunakan Teknik Petak Johari dengan Layanan Bimbingan Kelompok untuk meningkatkan Keterbukaan Diri (Self-Disclosure) siswa. Petak johari menyajikan sebuah model yang dapat digunakan untuk belajar lebih mengenal diri seseorang, itulah sebabnya penulis menggunakan teknik ini untuk meningktakan keterbukaan diri (SelfDisclosure) siswa. Penulis merasa permasalahan ini perlu segera dientaskan agar nantinya siswa atau individu yang mengalami masalah pengungkapan diri tidak berlarut menutup dirinya sehingga pola pikir dan rasa percaya kurang ada pada diri individu, karena setiap individu tentunya membutuhkan seorang teman atau sahabat yang mengenal dan dapat dipercaya agar dapat saling memotivasi satu sama lain dalam hubungan sosial.

Berdasarkan latar belakang yang telah dikemukakan di atas, hal ini mendorong peneliti untuk mengadakan penelitian terhadap Keterbukaan Diri (Self-Disclosure) siswa SMA Negeri 2 Kota Bengkulu, oleh karena itu dipandang cukup penting untuk mengadakan penelitian tentang muatan materi pendidikan keterbukaan diri (SelfDisclosure) dan keadilan dalam kehidupan berbangsa dan bernegara serta pelaksanaannya di sekolah, yang berjudul "Peningkatan Keterbukaan Diri (Self-Disclosure) Dengan Teknik Petak Johari Melalui Bimbingan Kelompok di SMA Negeri 2 Kota Bengkulu Kelas X MIPA F Tahun Ajaran 2015/2016".

Tujuan penelitian ini adalah agar siswa dapat meningkatkan Keterbukaan Dirinya. Melalui Petak Johari individu dapat mengetahui seperti apa persepsi orang lain terhadap dirinya dan individu dapat mengungkapkan keadaan yang tersembunyi secara sukarela mencerminkan mengenai dirinya kepada orang lain, sehingga orang tersebut menjadi senang karena mendapatkan informasi langsung dari yang bersangkutan daripada sumber-sumber lain.

Dari penelitian ini diharapkan siswa akan dapat mengentaskan masalahnya secara pribadi yang berhubungan dengan komunikasi antarpribadi, diharapkan siswa akan mendapatkan pemahaman dan ilmu baru tentang bagaimana memiliki sikap terbuka dan pentingnya keterbukaan diri (Self-Disclosure) itu sendiri. Bagi konselor sekolah Penelitian ini diharapkan dapat membantu Konselor Sekolah dalam mengoptimalisasi Keterbukaan Diri (SelfDisclosure) siswa serta sebagai inovasi 
dalam meningkatkan Keterbukaan Diri (Self-Disclosure) siswa sekaligus dapat memberikan informasi tentang bagaimana cara meningkatkan Keterbukaan Diri (SelfDisclosure) Siswa.

\section{Metode}

Metode yang digunakan dalam penelitian adalah penelitian tindakan kelas. Subjek penelitian adalah siswa kelas XI MIPA F SMA N 2 Kota Bengkulu. Prosedur penelitian tindakan kelas dilaksanakan melalui 4 (empat) tahap yaitu 1) perencanaan, 2) pelaksanaan, 3) Observasi, 4) Refleksi. Teknik pengumpulan data yang digunakan yaitu observasi (pengamatan) dan kuisioner (Angket). Untuk menganalisis data penelii menggunakan teknik deskriptif kuantitatif, yakni dengan memaparkan secara kuantitatif tentang peningkatan Keterbukaan Diri (Self-Disclosure) siswa melalui Bimbingan kelompok dengan teknik Petak Johari. Data yang diperoleh dalam penelitian tindakan kelas dianalisis dengan menggunakan cara kuantitatif sederhana, yakni dengan presentase $(\%)$. (Ermalinda \& Paizaluddin, 2014:135).

\section{Hasil Penelitian}

Untuk mempermudah dan memperjelas penjabarannya, dalam penelitian ini akan dipaparkan hasil penelitian meliputi (1)Tingkat keterbukaan diri siswa sebelum diberi layanan Bimbingan Kelompok dengan teknik Petak Johari. (2) Tingkat Keterbukaan Diri siswa setelah diberikan layanan Bimbingan kelompok dengan teknik petak johari.

\section{Tingkat Keterbukaan Diri siswa sebelum diberikan Layanan Bimbingan Kelompok Teknik Petak johari.}

Siswa diberi Pre test dengan jumlah 30 siswa kemudian terpilihlah 8 siswa dengan Keterbukaan diri rendah untuk dijadikan sampel dalam pelaksanaan Bimbingan kelompok. Hasil Pre test skala Keterbukaan Diri dapat dilihat dari tabel dibawah inI. 


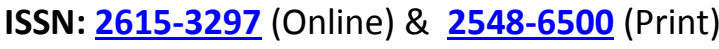

Tabel 1

Daftar siswa yang dijadikan subjek dalam penelitian

\begin{tabular}{|c|c|c|c|}
\hline \multirow{2}{*}{ No } & \multirow{2}{*}{ Kode Siswa } & \multicolumn{2}{|c|}{ Pre Test } \\
\cline { 3 - 4 } & & Skor & Kategori \\
\hline 1 & DWNT & 75 & Rendah \\
\hline 2 & TRH & 79 & Rendah \\
\hline 3 & TRNC & 99 & Sedang \\
\hline 4 & MEK & 79 & Rendah \\
\hline 5 & ZHR & 99 & Sedang \\
\hline 6 & AGH & 77 & Rendah \\
\hline 7 & ARN & 75 & Rendah \\
\hline 8 & CYNT & 88 & Sedang \\
\hline
\end{tabular}

Tabel 2

Distribusi Frekuensi tingkat Keterbukaan Diri siswa SMA N 2 Kota Bengkulu

\begin{tabular}{|c|c|c|c|}
\hline Interval & Kategori & Frekuensi & \% \\
\hline $130>$ & Sangat Tinggi & & \\
\hline $105-129$ & Tinggi & & \\
\hline $80-104$ & Sedang & 3 & $37,5 \%$ \\
\hline $55-79$ & Rendah & 5 & $62,5 \%$ \\
\hline $30-54$ & Sangat Rendah & & \\
\hline
\end{tabular}

2. Tingkat Keterbukaan Diri siswa setelah diberikan Layanan Bimbingan Kelompok Teknik Petak Johari.

a. Hasil Penelitian Siklus I

Tabel 3

Hasil instrumen setelah siklus satu

\begin{tabular}{|l|c|c|c|}
\hline No & Kode Siswa & Skor & Kategori \\
\hline 1 & DWNT & 88 & Sedang \\
\hline 2 & TRH & 100 & Sedang \\
\hline 3 & TRNC & 103 & Sedang \\
\hline 4 & MEK & 99 & Sedang \\
\hline 5 & ZHR & 112 & Tinggi \\
\hline 6 & AGH & 100 & Sedang \\
\hline 7 & ARN & 99 & Sedang \\
\hline 8 & CYNT & 106 & Tinggi \\
\hline
\end{tabular}


Berdasarkan hasil siklus satu diperoleh gambaran Keterbukaan Diri (Self-Disclosure) siswa, dengan jumlah siswa dengan tingkat Keterbukaan Diri sedang sebanyak 6 siswa dan tingkat
Keterbukaan Diri tinggi sebanyak 2 siswa, maka distribusi skor hasil frekuensi tingkat Keterbukaan Diri (Self-Disclosure) yang menjadi sampel dapat dilihat pada tabel 4 di bawah ini:

Tabel 4

Distribusi Frekuensi Keterbukaan Diri (Self-Disclosure)

\begin{tabular}{|c|c|c|c|}
\hline Interval & Kategori & Frekuensi & \% \\
\hline $130>$ & Sangat Tinggi & & \\
\hline $105-129$ & Tinggi & 2 & $25 \%$ \\
\hline $80-104$ & Sedang & 6 & $75 \%$ \\
\hline $55-79$ & Rendah & & \\
\hline $30-54$ & Sangat Rendah & & \\
\hline
\end{tabular}

a) pengamatan dan Observasi

Dilihat dari kegiatan bimbingan kelompok siswa masih malu-malu mengungkapkan pendapat, mereka lebih sering menunjuk teman yang lain untuk berpendapat, mereka masih enggan berbicara dan masih tertutup.

b) Analisis dan Refleksi

Hasil yang diperoleh dari penelitian siklus I ini adalah pada tahap observasi dan evaluasi dianalisis, kelemahan-kelemahan atau kekurangan-kekurangan yang terjadi pada setiap siklus akan diperbaiki pada siklus berikutnya. Pelaksanaan Bimbingan kelompok pada tahap ini menurut Guru BK sebagai observer kurang baik, seperti penjelasan materi dan kurangnya suasana yang hangat, namun pelaksana layanan sudah mampu berbicara dengan baik dalam memberikan penjelasan kepada anggota kelompok.

\section{b. Hasil penelitian Siklus II}

a) Pengamatan dan Observasi

Dilihat dari kegiatan bimbingan kelompok siswa sudah mulai terlihat aktiv, mereka sudah mau berpendapat, bercerita secara sukarela dan tidak ragu, mereka juga sudah mulai memahami diri mereka.

b) Analisis dan Refleksi

Hasil yang diperoleh dari penelitian siklus II ini adalah pada tahap observasi dan evaluasi dianalisis, kelemahan-kelemahan atau kekurangan-kekurangan yang terjadi pada setiap siklus akan diperbaiki pada siklus berikutnya. Pelaksanaan 
Bimbingan kelompok pada tahap ini menurut Guru BK sebagai observer sudah cukup baik, pemimpin kelompok mampu memasukan diri dalam kelompok, mampu menjelaskan

materi dengan baik

\section{Tabel 5}

Hasil instrumen setelah siklus tiga

\begin{tabular}{|l|c|c|c|}
\hline No & Kode Siswa & Skor & Kategori \\
\hline 1 & DWNT & 94 & Sedang \\
\hline 2 & TRH & 121 & Tinggi \\
\hline 3 & TRNC & 121 & Tinggi \\
\hline 4 & MEK & 129 & Tinggi \\
\hline 5 & ZHR & 123 & Tinggi \\
\hline 6 & AGH & 127 & Tinggi \\
\hline 7 & ARN & 110 & Tinggi \\
\hline 8 & CYNT & 114 & Tinggi \\
\hline
\end{tabular}

Berdasarkan hasil siklus satu 7 siswa, maka distribusi skor hasil diperoleh gambaran Keterbukaan Diri (Self-Disclosure) siswa, dengan tingkat frekuensi tingkat Keterbukaan Diri (Self Keterbukaan Diri sedang sebanyak 1 siswa Disclosure) yang menjadi sampel dapat dan tingkat Keterbukaan Tinggi sebanyak

Tabel 6

Distribusi Frekuensi Keterbukaan Diri (Self-Disclosure)

\begin{tabular}{|c|c|c|c|}
\hline Interval & Kategori & Frekuensi & \% \\
\hline $130>$ & Sangat Tinggi & & \\
\hline $105-129$ & Tinggi & 7 & $87,5 \%$ \\
\hline $80-104$ & Sedang & 1 & $12,5 \%$ \\
\hline $55-79$ & Rendah & & \\
\hline $30-54$ & Sangat Rendah & & \\
\hline
\end{tabular}

a) Pengamatan dan Observasi

Dilihat dari kegiatan bimbingan kelompok yang dilaksanakan dari siklus I sampai siklus III, siswa mampu bersikap positive dilihat dari keaktivan mereka dalam mengikuti rangkaian Bimbingan Kelompok selalu memiliki perubahan yang baik pada setiap siklusnya.

b) Analisis dan Refleksi

Hasil yang diperoleh dari penelitian ini adalah pada tahap observasi dan evaluasi dianalisis, kemudian dilakukan refleksi yaitu hasil kegiatan sudah memenuhi 
harapan yakni adanya perubahan meningkatkan keterbukaan diri tingkat Keterbukaan diri siswa. siswa.

\section{Layanan bimbingan kelompok teknik petak johari dapat}

Tabel 7

Data hasil angket awal sebelum pelaksanaan bimbingan kelompok dan setelah pelaksanaan bimbingan kelompok.

\begin{tabular}{|c|c|c|c|c|}
\hline Responden & $\begin{array}{c}\text { Skor sebelum } \\
\text { diadakan } \\
\text { bimbingan } \\
\text { kelompok }\end{array}$ & Kategori & $\begin{array}{c}\text { Skor sesudah } \\
\text { diadakan } \\
\text { bimbingan } \\
\text { kelompok }\end{array}$ & Kategori \\
\hline DWNT & 75 & Rendah & 94 & Sedang \\
\hline TRH & 79 & Rendah & 121 & Tinggi \\
\hline TRNC & 99 & Sedang & 121 & Tinggi \\
\hline MEK & 79 & Rendah & 129 & Tinggi \\
\hline ZHR & 99 & Sedang & 123 & Tinggi \\
\hline AGH & 77 & Rendah & 127 & Tinggi \\
\hline ARN & 75 & Rendah & 110 & Tinggi \\
\hline CYNT & 88 & Sedang & 114 & Tinggi \\
\hline
\end{tabular}

Dapat dilihat dari tabel 7 perubahan skor keterbukaan diri siswa berada pada tingkat rendah dan sedang dengan beberpa pertimbngan dari guru pembimbing dan setelah diadakan layanan bimbingan kelompok selama tiga siklus tingkat keterbukaan diri siswa menjadi sedang dan tinggi. Dengan demikian layanan bimbingan kelompok dengan teknik petak johari efektif dalam meningkatkan keterbukaan diri siswa.

\section{Pembahasan}

Berdasarkan hasil penelitian tentang Peningkatan Keterbukaan Diri dengan teknik petak johari melalui bimbingan kelompok kelas X MIPA F tahun Ajaran
2015/2016 di SMA N 2 Kota bengkulu. Dapat diketahui bahwa adanya peningkatana keterbukaan diri terhadap siswa. Analisis data menunjukkan bahwa bimbingan kelompok teknik petak johari dapat mengupayakan peningkatan keterbukaan diri siswa. Keterbukaan diri siswa disekolah sebelum mengikuti layanan bimbingan kelompok berada pada kategori rendah dan sedang, hal ini dapat dilihat dari hasil intrumen angket yang telah dilaksanakan. Dari hasil angket terdapat 8 siswa (sampel) dari 30 siswa yang tingkat keterbukaan dirinya rendah dan sedang, pada kualifikasi rendah yaitu $62,5 \%$ (5 siswa)dan kualifikasi sedang $37,5 \%$ (3 siswa). Setelah mengikuti 


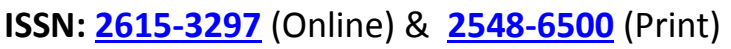

bimbingan kelompok dari siklus I sampai siklus III telah mengalami peningkatan menjadi kualifikasi rendah menjadi sedang $12,5 \%$ (1 siswa) dan kualifikasi sedang menjadi tinggi 87,5\% (7 siswa).

Pembukaan diri atau Self-Disclosure adalah mengungkapkan reaksi atau tanggapan kita terhadap situasi yang sedang kita hadapi serta memberikan informasi tentang masa lalu yang relevan atau yang berguna untuk memahami tanggapan kita dimasa kini (Johnson 1981 dalam Supraktiknya.1995: 14).

Layanan Bimbingan Kelompok yaitu layanan Bimbingan yang memungkinkan sejumlah peserta didik secara bersamasama memperoleh berbagai bahan dari narasumber tertentu (terutama dari pembimbing/konselor) yang berguna untuk menunjang kehidupannya sehari-hari baik individu maupun sebagai pelajar, anggota keluarga dan masyarakat serta untuk pertimbangan dalam pengambilan keputusan. (Dewa Ketut, 2008 : 64).

Setelah dilaksanakan bimbingan kelompok dengan teknik petak johari dalam proses penelitian sebanyak tiga siklus, maka hasil akhir dari proses pelaksanaan layanan bimbingan kelompok untuk meningkatkan keterbukaan diri siswa adalah berhasil.

\section{Penutup}

\section{Kesimpulan Dan Saran}

\section{a. Kesimpulan}

Berdasarkan hasil penelitian dan analisis data yang telah peneliti lakukan pada siswa SMA N 2 Kota Bengkulu untuk membantu siswa meningkatkan keterbukaan diri siswa dengan layanan bimbingan kelompok, maka diperoleh kesimpulan sebagai berikut:

1. Sebelum dilaksanakan layanan Bimbingan Kelompok tingkat Keterbukaan Diri siswa rendah dan sedang. Siswa dengan tingkat Keterbukaan Diri rendah sebanyak 5 siswa dengan presentase $62.5 \%$, siswa dengan tingkat Keterbukaan Diri sedang sebanyak 3 siswa dengan presentase $37,5 \%$.

2. Setelah dilaksanakan Bimbingan Kelompok dengan Teknik Petak Johari sebanyak tiga siklus tingkat Keterbukaan Diri siswa meningkatkan menjadi sedang dan tinggi. Siswa dengan tingkat Keterbukaan Diri sedang sebanyak 1 siswa dengan presentase 12,5\%, siswa dengan tingkat Keterbukaan Diri tinggi sebanyak 7 siswa dengan presentase $87,5 \%$.

3. Layanan Bimbingan Kelompok Teknik Petak Johari dapat digunakan 
untuk membantu meningkatkan

Keterbukaan Diri siswa.

\section{b. Saran}

Lembaga sekolah dapat menyediakan berbagai instrumen bagi guru pembimbing agar dapat mengungkapkan masalah-masalah yang dialami oleh siswa serta meningkatkan kinerja guru pembimbing terutama di dalam bidang layanan konseling.

Bagi gurur BK Sebagai salah satu upaya untuk meningkatkan Keterbukaan Diri siswa, diharapkan dapat melaksanakan layanan bimbingan kelompok dan melaksanakan kegiatankegiatan lain yang dapat membantu memecahkan permasalahan siswa di sekolah dan untuk memotivasi siswa dalam hal lainnya yang lebih bermanfaat.

Bagi peserta didik setelah mengikuti layanan bimbingan kelompok siswa dapat memanfaatkan pelayanan tersebut untuk mengoptimalkan diri karena layanan bimbingan kelompok dapat digunakan sebagai sarana untuk berkomunikasi, memahami suatu permasalahan individu dan bersosialisasi serta melatih diri untuk membuka diri. Serta bagi peneliti laiannya Perlu dilakukan penelitian yang serupa dengan mempelajari kelemahankelemahan dalam penelitian, ataupun dengan mengembangkan penelitian ini dengan dilatarbelakangi oleh konteks yang berbeda agar dapat membandingkan temuan dari hasil penelitian ini.

\section{Daftar Rujukan}

Hutagalung Inge.2007.Pengembangan Kepribadian.Jakarta: PT Indeks.

Liliweri Alo. 1991. Komunikasi Antar Pribadi. Bandung: PT Citra Aditya Bakti.

Morton. 1985. Pengertian Membuka Diri (Self-Disclosure). Tersedia: http://www.kajianteori.com/ 2013/02/pengertianmembuka-diri-selfdisclosure.html (16 Juni 2016).

Morrisan. 2002. Psikologi Komunikasi. Bogor: Ghalia Indonesia.

Nurihsan. J. A. 2012. Strategi Layanan Bimbingan Dan Konseling. Bandung: PT Refika Aditama.

Paizaludin, E.2014.Penelitian Tindakan Kelas.Bandung: Alfabeta.

Pangaribuan.D. 2015. Pengembangan Keterbukaan Diri (SelfDisclosure). Tersedia: http://.bppk.kemenkeu.go.id /publikasi/artikel/168- 
ANIK FEBRIYANTI

ISSN: 2615-3297 (Online) \& 2548-6500 (Print)

artikel-pengembangan-

sdm/21470-keterbukaan-

diri-self-disclosure (23 Juni

2016)

Prayitno. 1995. Buku Seri Bimbingan Dan

Konseling Kelompok.

Layanan Bimbingan Dan

Konseling Kelompok.

Jakarta: Ghalia Indonesia.

Rakhmat, J. 2005. Psikologi Komunikasi.

Bandung: PT.Remaja

Rosdakarya.

Sugiyarti,R.2009. Meningkatkan

Keterbukaan Diri Dalam

Mengemukakan Pendapat

Melalui Layanan

Bimbingan Kelompok

Kepada beberapa Siswa

Kelas XI Di SMA N 14

Semarang. Universitas

Negri Semarang: Tidak

diterbitkan.

Tersedia:https://www.googl

e.co.id/webhp?sourceid=chr ome-

instant\&ion=1\&espv=2\&ie

$=\mathrm{UTF}-$

8\#q=angket\%20ketrbukaan

\%20diri (Senin 27 Juni

2016).

Suratno. 2011. Komunikasi Interpersonal. Yogyakarta: Graha Ilmu.

Sukardi,D.K. 2008. Pengantar

Pelaksanaan Program

Bimbingan Dan Konseling

Disekolah. Jakarta: Rineka

Cipta.

Sugiyono. 2014. Metode Penelitian

Kuantitatif kualitatif dan

$R \& D$. Bandung: Alfabeta.

Supraktiknya.A.1995.Komunikasi

Antarpribadi.Yogyakarta: PT Kanisius.

Wood, T. 2012. Komunikasi Teori dan Praktik. Jakarta: Salemba Humanika. 
JURNAL PSIKODIDAKTIKA || VOL: 3, NO: 1 Juni 2018 | 32 | 


\section{ANIK FEBRIYANTI}

ISSN: $\underline{2615-3297}$ (Online) \& 2548-6500 (Print) 